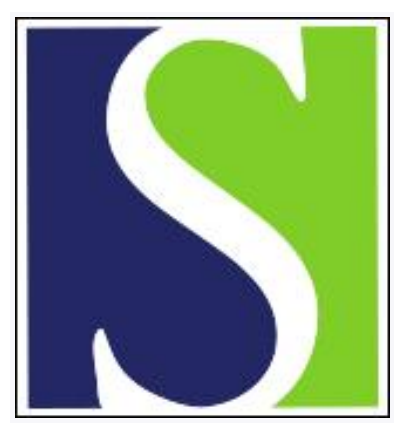

Scand J Work Environ Health 1986;12(2):114-120

https://doi.org/10.5271/sjweh.2169

Issue date: Apr 1986

Decreased blood lead levels in residents of Stockholm for the period 1980-1984.

by Elinder CG, Friberg L, Lind B, Nilsson B, Svartengren M, Overmark I

This article in PubMed: www.ncbi.nlm.nih.gov/pubmed/3726492

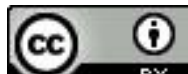




\title{
Decreased blood lead levels in residents of Stockholm for the period $1980-1984$
}

\author{
by Carl-Gustaf Elinder, MD, ${ }^{1}$ Lars Friberg, MD, ${ }^{2}$ Birger Lind, ${ }^{2}$ Bo Nilsson, ${ }^{2}$ \\ Magnus Svartengren, ${ }^{2}$ Ingela Övermark, $\mathrm{MD}^{3}$
}

\begin{abstract}
ELINDER C-G, FRIBERG L, LIND B, NILSSON B, SVARTENGREN M, ÖVERMARK I. Decreased blood lead levels in residents of Stockholm for the period 1980-1984. Scand J Work Environ Health 12 (1986) 114-120. A number of measures have been taken to decrease the spread of lead to ambient air and food. In a study of the effect of these and other preventive measures, blood samples from approximately 100 persons living in the inner city area of Stockholm were collected and analyzed for lead content on three different occasions, in 1980,1983, and 1984. The same subjects were examined on at least two occasions and the analytical method, atomic absorption spectrophotometry, was carefully controlled by means of reference samples on each occasion. The blood lead levels decreased during the observation period. The average blood lead concentrations for all the examined persons were $0.37,0.26$, and $0.25 \mu \mathrm{mol} / 1$ for 1980,1983 , and 1984 , respectively. The mean of the differences in individual blood lead levels for 1980 and 1984 was $0.12 \mu \mathrm{mol} / 1$. This figure corresponds to an average decrease in blood lead of $34 \%$ for all the subjects examined in 1980 . The decrease occurred mainly during the period 1980-1983 (mean $0.11 \mu \mathrm{mol} / \mathrm{l}$ ) and, thereafter, was only slight for the period $1983-1984$ (mean $0.01 \mu \mathrm{mol} / \mathrm{l}$ ). Factors such as age, sex, and change of residence during the observation period did not influence the final results.
\end{abstract}

Key terms: ambient air, analytical quality control, atomic absorption spectrophotometry (AAS), electrothermal atomization (ETA), food, gasoline.

Health risks resulting from pollution of the general environment by lead have been extensively discussed in the last decade (17). The debate has especially focused on the health risks to young children and fetuses $(14,18)$.

The principal source of exposure for the general population, ie, persons not occupationally exposed to lead, is lead in foodstuffs. Inhalation of lead from ambient air may, however, also be an important source of exposure (10). Other sources are peroral exposure from fingers contaminated by dust and dirt containing lead and lead-contaminated canned food, drinking water, and beverages $(7,14)$.

In 1980 , we (7) determined the lead concentration of blood samples from 423 residents of Stockholm. The results showed that the average blood lead level of the subjects examined was relatively low $(0.38$ $\mu \mathrm{mol} / \mathrm{l})$ compared to that in several other countries (26). Men and smokers had somewhat higher levels (approximately $20 \%$ higher) in comparison to women and nonsmokers, respectively. There was also a posi-

1 Department of Occupational Medicine and Research Department, National Board of Occupational Safety and Health, S-171 84 Solna, Sweden.

2 Department of Environmental Hygiene, Karolinska Institute, and National Institute of Environmental Medicine, S-104 01 Stockholm, Sweden.

3 Medicine Clinic, Karolinska Hospital, S-104 01 Stockholm, Sweden.

Reprint requests to: Dr C-G Elinder, Research Department, National Board of Occupational Safety and Health, S-171 84 Solna, Sweden. tive correlation between alcohol consumption (especially wine), as stated by the subjects, and blood lead levels.

In recent years a number of measures have been introduced to decrease exposure to lead in the general population of Sweden. The level of lead in foodstuffs has decreased, partly due to the fact that the food industry has successively replaced soldered food cans by welded or solid piece cans. The use of lead in gasoline has also decreased as a result of legislative measures taken in 1981, which lowered the highest permissible level from 1.9 to $0.7 \mathrm{mmol}$ (from 0.4 to $0.15 \mathrm{~g}$ ) per liter of gasoline.

The present study was carried out to follow up the study from 1980 and to answer, if possible, the question of whether the recent measures to decrease environmental exposure to lead have had any effect.

\section{Material and methods}

\section{Populations examined}

Only subjects from whom blood samples were obtained in 1980 (7) were included in the present study. These subjects were requested to give new blood samples in 1983 and 1984 . The lead concentrations of the individual blood samples for 1983 and 1984 were compared to those of 1980 .

All of the 214 randomly selected subjects from the inner city area of Stockholm who took part in the 1980 study were primarily considered as participants in the 
1983 study. Of the 214 subjects, $47 \%(\mathrm{~N}=100)$ gave another blood sample in 1983. The reasons for nonparticipation can be found in figure 1. The group of 100 subjects who participated both in 1980 and 1983 were again asked to take part in 1984. Of these 100 subjects, 81 provided us with a third blood sample. Once again the reasons for nonparticipation are given in figure 1.

As it was planned in the study protocol to examine 100 subjects, another 41 subjects were selected from the group which had submitted blood samples in 1980 and who resided either close to or at a short distance from streets with heavy traffic in the inner city area of Stockholm $(7,24)$. Of these 41 subjects primarily considered, $18(43 \%)$ participated in the follow-up study in 1984 (figure 1).

A third group comprising 13 comparable subjects was obtained from the study on environmental exposure to lead and blood lead levels carried out in collaboration with the World Health Organization in 1983 (4) (figure 1).

The groups examined, the number of persons considered, the dropouts and participants, and the actual number of blood samples analyzed are presented schematically in figure 1. For a total of 113 individual samples it was possible to compare data on blood lead from 1980 and 1983. For 1980 to 1984,99 blood samples could be compared, and, for 1983 to 1984,81 blood samples could be compared.

The blood samples were collected at different times of the year. In order to prevent interference due to seasonal variation (3), the blood samples in 1984 were collected at the same time of the year ( $\pm 14 \mathrm{~d}$ ) as the samples from 1980. Thus 209 weeks $(4 \times 52.2)$ ( $\pm 14 \mathrm{~d}$ ) had elapsed between the time of sampling in 1980 and that in 1984. About six months (on the average 32 weeks) elapsed between the time of sampling in 1983 and that in 1984.

Personal data for each subject were compiled concomitant to the taking of the blood samples collected in 1980, 1983, and 1984. The data collected included place of residence (address), occupation, possible occupational exposure, possible exposure to lead during recreation, smoking habits, and alcohol consumption.

\section{Sampling and analytical methods}

Blood samples (approximately $10 \mathrm{ml}$ ) were taken from a superficial elbow vein and collected in evacuated
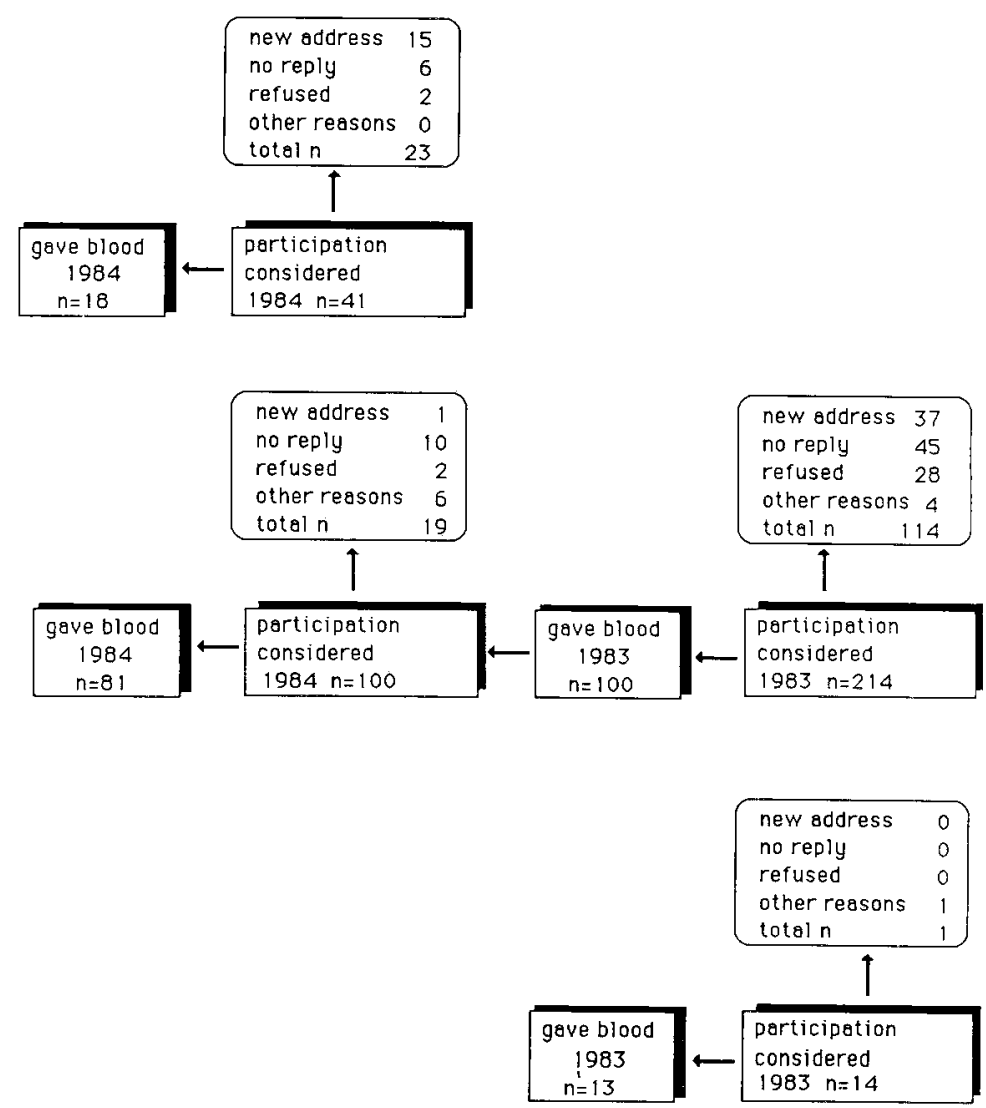

Complementary sample of residents from inner city area of Stockholm

Figure 1. Schematic presentation of the groups examined, the number of persons considered, the reasons for nonparticipation, and the submitted and analyzed blood samples. (WHO = World Health Organization) 
Venoject blood collection tubes containing about 140 units of sodium heparin. Special precautions were taken to avoid any contamination. The tubes were inverted gently several times to mix the heparin and blood and thus prevent coagulation. The samples were subsequently subdivided into samples of $2-3 \mathrm{ml}$ in acid-washed polyethylene tubes. The tubes were stored at $-20^{\circ} \mathrm{C}$ until the analysis. To avoid the risk of sample contamination, random samples from each batch of analytical materials used (tubes, needles, pipettes, etc) were carefully examined before the blood sampling. Essentially identical materials and methods of sampling were utilized in 1980, 1983, and 1984 (7).

Duplicates of $0.3 \mathrm{ml}$ of whole blood from the stored sample were deproteinized by the addition of $0.5 \mathrm{ml}$ of $0.8 \mathrm{M}$ nitric acid. After being thoroughly mixed and centrifuged, the supernatants were transferred to acidwashed polyethylene cups in an automatic sample injector (AS-1 or AS-40).

Lead was determined by atomic absorption spectrophotometry (AAS), Perkin-Elmer 373, via electrothermal atomization (ETA), HGA 500, and by the use of a deuterium background correction system. Standards or test solutions $(20 \mu \mathrm{l})$ were injected with the automatic sampler into standard graphite tubes.

The areas under the atomization signal peaks were integrated by the instrument, printed out on a PerkinElmer PRS-10 printer, and used for evaluating the results. A Perkin-Elmer 56 two-pen recorder was utilized to check the electrothermal program. One pen recorded the shape and peak height of the deuteriumcompensated lead signals. The other recorded the nonspecific absorption of the light emitted by the deuterium lamp.

Calibration solutions were prepared by the addition of known amounts of lead to blood from cows. The same sample treatment and instrumental analysis were used throughout the study, and further information can be obtained from previous reports $(7,27)$.

Analytical accuracy was confirmed for each analytical occasion by means of internal quality control and external quality control (EQC) samples. The lead concentration in the samples of the internal quality control was known to the analyst and to those who processed the analytical data, whereas the samples of the external quality control contained an unknown concentration of lead. A total of 18 samples from the former and 120 samples from the latter were analyzed parallel to the blood samples from the examined subjects. Figures 2 and 3 illustrate the combined results of the external quality control for the analyses carried out in 1980 and 1984. The agreement between results obtained in our laboratory and the reference values was very good, and the results of all quality control runs (20 runs, 6 samples in each run) fell within the acceptance intervals used within the framework of a global program for the biological monitoring of metals (26).

The precision, expressed as the average $(\overline{\mathrm{x}})$ relative standard deviation (SD) of the duplicates $\left(\mathrm{SD}_{\mathrm{i}} / \overline{\mathrm{x}}_{\mathrm{i}}\right)$, was 4,4 , and $10 \%$ for the 1980,1983 , and 1984 analytical runs, respectively.

The results are given as micromoles of lead per liter of blood, and 0.1 and $0.3 \mu \mathrm{mol} / 1$ correspond to 20.7 and $62.2 \mu \mathrm{g} / \mathrm{l}$ or $2.07 \mu \mathrm{g} / \mathrm{dl}$ and $6.22 \mu \mathrm{g} / \mathrm{dl}$, respectively.

\section{Results}

The average blood lead levels of all the subjects examined were 0.37 (SD 0.16), 0.26 (SD 0.16), and 0.25 (SD 0.15) $\mu \mathrm{mol} / 1$ for 1980,1983 , and 1984, respectively. The average blood lead level of the 138 subjects examined in 1980 only was somewhat higher [mean

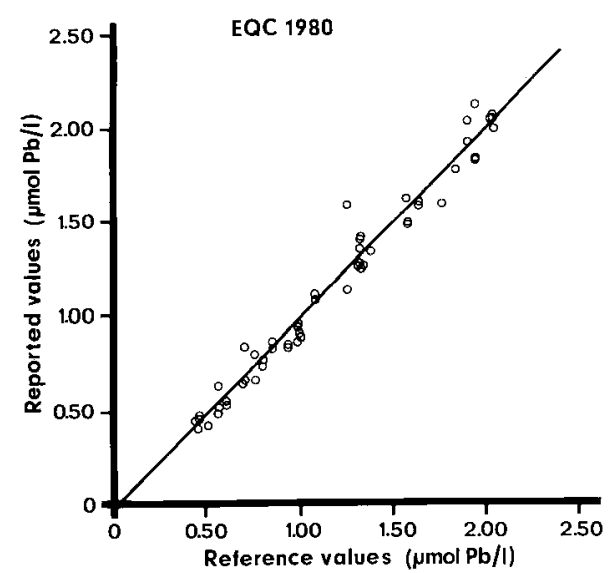

Figure 2. Comparison between the determined levels of lead in blood and reference values (EQC) for 1980 (regression line $y=-0.041+1.02 x, r=0.99, N=54$ )

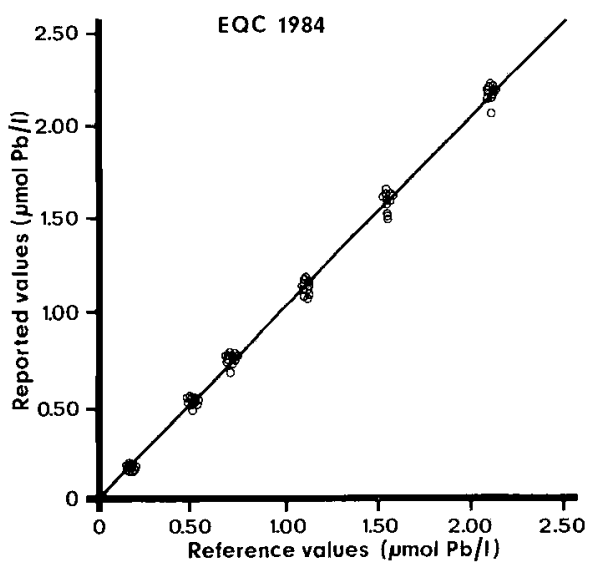

Figure 3. Comparison between the determined levels of lead in blood and reference values (EQC) for 1984 (regression line $y=0.001+1.02 x, r=0.99, N=66$ ). 
Table 1. Average decrease in the blood lead concentration between 1980 and 1983, 1983 and 1984, and 1980 and 1984 .

\begin{tabular}{|c|c|c|c|c|c|c|c|c|c|}
\hline \multirow{3}{*}{ Group } & \multicolumn{3}{|c|}{$1980-1983$} & \multicolumn{3}{|c|}{$1983-1984$} & \multicolumn{3}{|c|}{$1980-1984$} \\
\hline & \multirow[t]{2}{*}{$\begin{array}{c}\text { Number } \\
\text { of subjects }\end{array}$} & \multicolumn{2}{|c|}{$\begin{array}{c}\text { Blood lead } \\
\text { concentration } \\
(\mu \mathrm{mol} / \mathrm{l})^{\mathrm{a}}\end{array}$} & \multirow[t]{2}{*}{$\begin{array}{c}\text { Number } \\
\text { of subjects }\end{array}$} & \multicolumn{2}{|c|}{$\begin{array}{c}\text { Blood lead } \\
\text { concentration } \\
(\mu \text { mol } / /)^{\mathrm{a}}\end{array}$} & \multirow[t]{2}{*}{$\begin{array}{c}\text { Number } \\
\text { of subjects }\end{array}$} & \multicolumn{2}{|c|}{$\begin{array}{c}\text { Blood lead } \\
\text { concentration } \\
(\mu \mathrm{mol} / \mathrm{l})^{\mathrm{a}}\end{array}$} \\
\hline & & Mean & SD & & Mean & SD & & Mean & SD \\
\hline Men & 59 & 0.12 & 0.10 & 39 & 0.01 & 0.01 & 43 & 0.13 & 0.10 \\
\hline $\begin{array}{l}\text { Women } \\
\text { Subjects with }\end{array}$ & 49 & 0.10 & 0.10 & 39 & 0.01 & 0.04 & 51 & 0.11 & 0.10 \\
\hline same address ${ }^{b}$ & 85 & 0.12 & 0.06 & 66 & 0.01 & 0.05 & 80 & 0.13 & 0.09 \\
\hline Random sample ${ }^{c}$ & 77 & 0.11 & 0.09 & 77 & 0.01 & 0.05 & 77 & 0.12 & 0.10 \\
\hline All subjects & 108 & 0.11 & 0.08 & 78 & 0.01 & 0.05 & 94 & 0.12 & 0.10 \\
\hline
\end{tabular}

a $0.1 \mu \mathrm{mol} / 1=20.7 \mu \mathrm{g} / \mathrm{l}$ or $2.07 \mu \mathrm{g} / \mathrm{dl}$.

b Persons that had changed address between the two dates were excluded.

c Only persons from a random sample (figure 1) who submitted blood samples on all three occasions (1980, 1983, and 1984).

0.40 (SD 0.15) $\mu \mathrm{mol} / 1$ ] compared to the average blood lead level of persons who participated in the followup study $(0.37 \mu \mathrm{mol} / \mathrm{l})$.

According to the answers given on the last questionnaire (1983 and/or 1984) it appeared that five of the subjects examined may have been additionally exposed to lead during work or recreation. These five subjects were excluded from the data processing. After the exclusion of these five subjects, the average values of the lead in blood were 0.36 (SD 0.15), 0.25 (SD 0.13), and 0.23 (SD 0.14) $\mu \mathrm{mol} / 1$ for 1980,1983 , and 1984, respectively. The data from 1980 and 1983 or 1984 were statistically significant $(p<0.01)$, but not those from 1983 and $1984(\mathrm{p}=0.5)$.

The mean differences in individual blood lead levels between the years 1980-1983, 1983-1984, and 1980-1984 are presented in table 1. Figure 4 shows the change which took place in the blood lead levels between 1980 and 1984. As can be seen from the figure, the blood lead concentration had decreased in almost all the subjects $(96 \%)$. The mean change in the individual levels between 1980 and 1984 was 0.12 (SD 0.10$) \mu \mathrm{mol} / 1$, which corresponds to an average individual decrease in blood lead of $34 \%$ between 1980 and 1984.

The decrease occurred mainly during the period $1980-1983(0.11 \mu \mathrm{mol} / \mathrm{l})$ and was highly statistically significant $(p<0.01)$ for this period, whereas the decrease for the period 1983-1984 was only slight $(0.01$ $\mu \mathrm{mol} / \mathrm{l})$ and did not attain two-sided statistical significance $(\mathrm{p}=0.08$ ). For the period 1980-1983 (approximately 176 weeks) the average individual decrease in blood lead was $0.6 \mathrm{nmol} / \mathrm{l}$ a week, while the decrease for the period 1983-1984 (approximately 32 weeks) was $0.3 \mathrm{nmol} / \mathrm{l}$ a week. For the whole period 19801984 (exactly four years) the average individual decrease in blood lead was $0.6 \mathrm{nmol} / \mathrm{l}$ a week.

The decreases in blood lead were similar for the men and women over the whole observation period (table 1). Fourteen subjects changed their place of residence during the period 1980-1984, but all the sub-

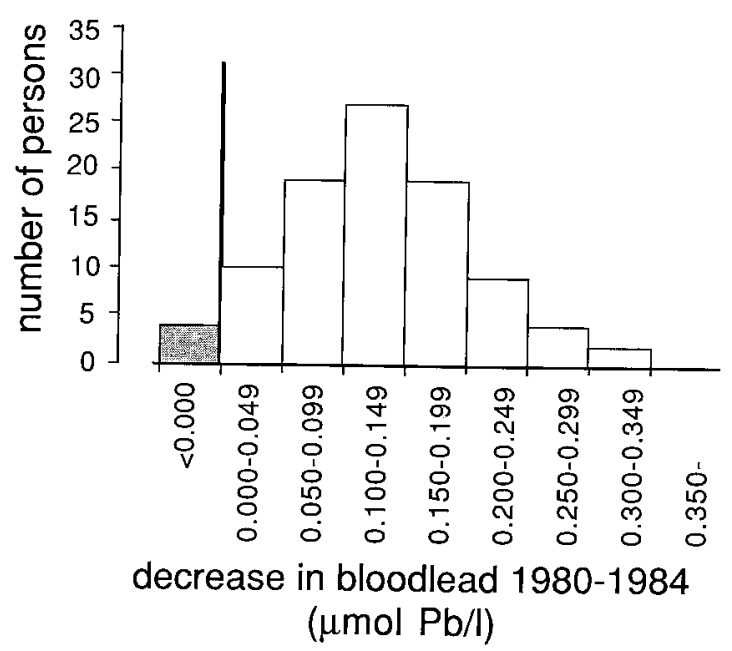

Figure 4. Frequency distribution of different subjects' change in blood lead level between 1980 and 1984.

jects still resided in Stockholm and, in most cases, within the inner city area. Excluding data on subjects who had changed address did not appreciably influence the results. Furthermore, the results were not affected even when the comparison between the years 1980, 1983 , and 1984 was limited to only those subjects examined on all three occasions (table 1 ).

No correlation was found between age and blood lead level, and the level decreased at the same rate for all age groups (figure 5). Similarly there were no systematic variations in the blood lead levels in relation to time of year when the samples were collected.

According to the questionnaires smoking habits and alcohol consumption were practically unaltered during the whole observation period; therefore, no division into categories according to smoking or alcohol habits was made. 


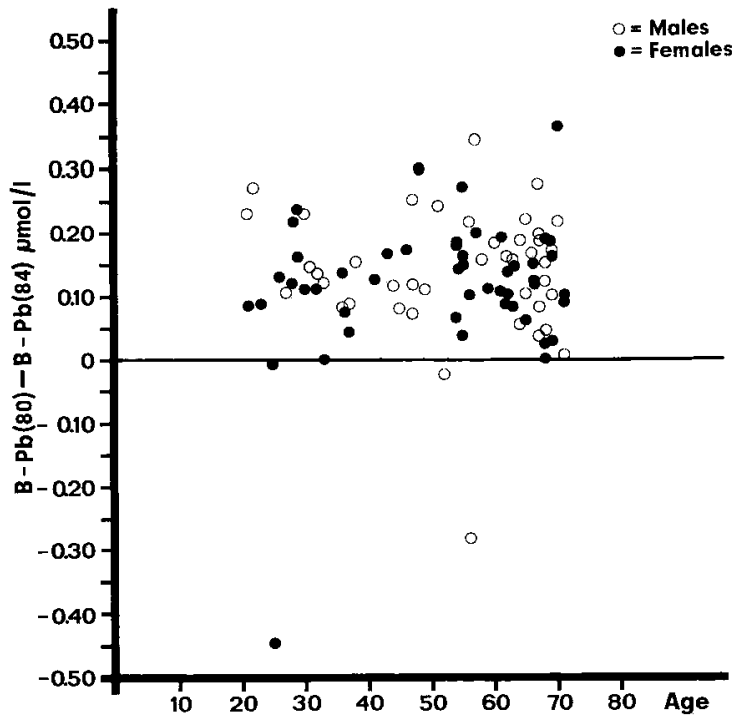

Figure 5. Differences in individual subjects' blood lead levels in 1980 [B-Pb (80)] and 1984 [B-Pb (84)] as a function of age (in years).

\section{Discussion}

This study began in 1980 and was terminated in 1984 . Several international studies on lead have been published in the interim. These studies verify the finding that the mean level of lead in blood in the general population has decreased $(1,8,13,16,20)$. The mean values for lead in almost 28000 blood samples from 64 different areas in the United States showed a significant downward trend over the period 1976-1980. On the average, lead in blood decreased by about $37 \%$ from February 1976 to February 1980 (1). It was considered that the most important reason for this decrease was the decrease in the use of lead in gasoline (1). In the United States lead levels in gasoline decreased by more than $50 \%$ over the period 19761980.

The conclusions drawn from the American studies have, however, been disputed $(9,12,15)$. Among other things, critics have pointed to the fact that personal characteristics, eg, race, sex, and age, as well as factors such as living conditions and degree of urbanization, all of which may be of influence, were not considered when the results were interpreted (15). Another problem in the American studies lies in the fact that the same subjects were not examined on the different occasions $(2,12)$. In addition the conclusion drawn, ie, that a decrease in the use of lead in gasoline was responsible for the decrease in the blood lead levels in the United States, has been questioned on the grounds that blood lead levels in England decreased during the period 1972-1982, in spite of the fact that very little change in the use of lead in gasoline had taken place during that period (8).
The present study is unusual in that the same subjects were examined on several occasions. Only persons residing in the inner city area of Stockholm in 1980 were included. Analyses were carefully controlled and evaluated on each occasion with both internal and external quality control. In our opinion there is, therefore, no doubt that the blood lead levels of the subjects examined did in fact decrease by approximately $30 \%$ during the period 1980-1984. One remaining problem is, however, the question of the extent to which these findings can be applied to the total population of the inner city area of Stockholm, or the general population of Sweden. Even though our aim was to study a random sample of the population in the inner city of Stockholm, it is obvious that the subjects examined did in fact comprise a selected group, ie, they agreed to come to the Karolinska Institute and to give blood samples on at least two occasions (figure 1). However, we have no reason to believe that there are any systematic differences in regard to lead exposure between our subjects and other residents of Stockholm. The subjects examined in 1980 did not have exceptionally high blood lead levels and could therefore be expected to approach the mean of the whole group on repeated sampling. In fact, the 138 persons from the 1980 study who did not participate in the follow-up study, had slightly higher blood lead levels than did those who participated in 1983 and 1984. The subjects received no information on how to avoid exposure to lead. Environmental exposure to lead should, therefore, have been the same as that of other residents of Stockholm. We are not however able to rule out the possibility that the subjects examined in 1980 became aware of environmental pollution in general, as a direct result of the tests, and, consequently, altered their ways of life. The subjects were, however, not informed that there would be a followup study, and the answers to the questionnaires did not give the impression that the subjects had modified their life-styles during the observation period.

What then are the reasons for the observed decrease in the blood lead levels? Several factors may have contributed. A decrease in the use of lead in gasoline and, consequently, the spread of lead to the atmosphere is, probably, one important contributory factor. Over the period 1979-1982 the mean of all measurements of ambient air in Stockholm decreased from 0.06 to 0.02 $\mu \mathrm{mol} / \mathrm{m}^{3}$ (from 1.2 to $0.5 \mu \mathrm{g} / \mathrm{m}^{3}$ ) (25). For two specific streets measurements were carried out with exactly the same measurement techniques, and it was seen that the lead levels in the air decreased by $50 \%$ (25). Calculating from experimental and epidemiologic data, Chamberlain (5) found a statistical correlation between lead in air and lead in blood. On the basis of this correlation it can be calculated that a reduction in individual air lead exposure from 0.06 to $0.02 \mu \mathrm{mol} / \mathrm{m}^{3}$ would result in a decrease in blood lead of $0.05-0.10$ $\mu \mathrm{mol} / 1(10-20 \mu \mathrm{g} / \mathrm{l})$. There are some data that suggest a curvilinear relationship between lead in air and 
lead in blood (11), although it has been disputed by others (23). If the relationship between lead in air and lead in blood is curvilinear, the effect of a decrease of lead in air on the blood lead level would be more pronounced at low levels of exposure.

A Norwegian study (6) suggested that the decrease found in blood lead could be as great as $0.15 \mu \mathrm{mol} / 1$ $(30 \mu \mathrm{g} / \mathrm{l})$. These estimates of the effect of a decrease of lead in air on blood lead level agree relatively well with what was found in the present study. We would like to point out though that our study did not have access to individual measures of exposure, eg, in the form of personal air sampling equipment. The only measures of exposure were the results of measurements carried out by the Stockholm Municipal Environment and Health Administration in a number of locations in the inner city area of Stockholm (25).

Levels of lead in air are not necessarily directly related to individual exposure. In our earlier study (7) subjects living close to streets carrying heavy traffic and subjects living outside the inner city area, and thus "probably less exposed to lead in air, were examined. No relationship between place of residence and blood lead level was found in that study (7). The parallel phenomena, decreasing air lead level and blood lead level, therefore, do not constitute evidence of causality.

A decrease in the intake of lead via food may also have been of major importance. Food can be contaminated by lead in several ways. The general spread of lead from car exhaust and from industry may contribute to lead levels normally found in foodstuffs. It is likely that a decrease in the emission of lead from car exhaust and from industry will result in decreasing levels of lead in the normal diet.

The concentration of lead in feces of 27 residents of Stockholm has recently been studied by Bruaux \& Svartengren (4). Feces contain ingested lead (approximately $90 \%$ ) which has not been absorbed by the gastrointestinal tract. On the assumption of a $10 \%$ gastrointestinal absorption, the mean value of lead in feces was $0.11 \mu \mathrm{mol} / \mathrm{d}(22 \mu \mathrm{g} / \mathrm{d})$, which is equivalent to a daily lead intake of about $0.12 \mu \mathrm{mol}(24 \mu \mathrm{g})$. In Sweden earlier estimations of daily lead intake via foodstuffs showed average intakes of 0.15 and 0.13 $\mu \mathrm{mol} / \mathrm{d}(30$ and $27 \mu \mathrm{g} / \mathrm{d})(19,21)$.

Lead in food can also originate from direct contamination in production and canning processes. In a study carried out by the National Swedish Food Administration (22) it was found that certain types of canned food could contain relatively high concentrations of lead, up to $20 \mu \mathrm{mol}(4.1 \mathrm{mg})$ per kilogram of fresh weight. Samples of 350 canned foods were examined over the period 1979-1981. The mean lead level in these samples was $0.87 \mu \mathrm{mol} / \mathrm{kg}(0.18 \mathrm{mg} / \mathrm{kg})$. It can be assumed, from these findings, that in 1980 the inhabitants of Stockholm consumed, on the average, $0.04 \mu \mathrm{mol} / \mathrm{d}(9 \mu \mathrm{g} / \mathrm{d})$ from lead-containing canned food. This figure is equivalent to $30 \%$ of the estimated total intake via food. In the 1980 s the food industry has begun to use lead-free cans instead of lead-soldered cans to a much greater extent than previously. This change is especially true for domestic production, but even for imported canned food the use of lead-containing solders has decreased. In view of the fact that lead in canned food constitutes, at the most, $30 \%$ $(0.04 \mu \mathrm{mol} / \mathrm{d})$ of the "normal" lead intake (approximately $0.15 \mu \mathrm{mol} / \mathrm{d}$ ), it seems unlikely that the decrease in the use of lead in canned food is the sole cause of decreasing blood lead levels. Unfortunately, there are no data on whether or not daily intake of lead via food, including or excluding, canned food, has changed over the last five years.

In conclusion, there has been a decrease in the use and emission of lead in Sweden and abroad over the period 1980-1984. This change has led to a decrease in exposure via food and other sources. As a consequence blood lead levels in the general population have decreased. The decreased use of lead in gasoline has probably been a major contributory factor, but other sources may also have contributed.

Although we cannot with certainty state the exact reasons for the approximately $30 \%$ decrease in blood lead levels over the period 1980-1984, the results are in themselves satisfactory from the point of view of health.

\section{Acknowledgments}

We are grateful to Ms U Björs, Ms K Sundstedt, and Ms S Åkerberg for their skillful assistance, especially in the analysis of lead in blood, and Mr R Ảberg for performing the interviews and carrying out some of the data programing. We are also grateful to Ms E Kessler, who has translated this report into English.

This project was supported by a grant from the $\mathrm{Na}$ tional Environment Protection Board, Research Council (contract 5311013-6) and the Swedish Petroleum Institute.

\section{References}

1. Annest JL, Pirkle JL, Makuc D, Neese JW, Bayse DD, Kovar MG. Chronological trend in blood lead levels between 1976 and 1980. N Engl J Med 308 (1983) 1373-1377.

2. Barry PSI. Lead in petrol. Lancet 2 (1982) 94.

3. Billick IH, Curran AS, Shier DR. Analysis of pediatric blood lead levels in New York City for 1970-1976. Environ Health Perspect 31 (1979) 183-190.

4. Bruaux P, Svartengren M, ed. WHO assessment of human exposure to lead: Comparison between Belgium, Malta, Mexico and Sweden. Karolinska Institute, Stockholm 1985. (Prepared for the United Nations Environment Programme and the World Health Organization).

5. Chamberlain AC. Effect of airborne lead on blood lead. Atmos Environ 17 (1983) 677-692.

6. Clench-Aas J, Thomassen Y, Levy F, Skaug K. Blood lead - A function of vehicular emissions and smoking. Norwegian Institute for Air Research, Lillestrøm 1984. 
7. Elinder C-G, Friberg L, Lind B, Jawaid M. Lead and cadmium levels in blood samples from general population of Sweden. Environ Res 30 (1983) 233-253.

8. Elwood PC. Changes in blood lead concentrations in women in Walen 1972-82. Br Med J 286 (1983) 15531555.

9. Elwood PC, Gallacher J. Blood lead levels, 1976-1980. N Engl J Med 310 (1984) 1125.

10. Gloag D. Sources of lead pollution. Br Med J 282 (1981) $41-44$.

11. Hammond PB, O'Flaherty EJ, Gartside PS. The impact of air-lead on blood-lead in man: A critique of the recent literature. In: Consultants Ltd. International conference on heavy metals in the environment, London, 18-21 September 1979. Edinburgh, 1979, pp 631-638.

12. Lynam DR, Hughmark GA, Fort BR Jr, Hall CA. Blood lead concentrations and gasoline lead usage. In: Consultants Ltd. International conference on heavy metals in the environment, Heidelberg, September 1983, Volume 1. Edinburgh 1983, pp 417-420.

13. Morbidity and Mortality Weekly Report. Blood lead levels in US population. Morb Mortal Wkly Rep 31 (1982) 132-134.

14. Oskarsson A, Camner P. Lead. In: Ewetz L, Camner $\mathrm{P}$, ed. Motor vehicles and cleaner air. Liber, Stockholm 1983, pp 43-73.

15. Pierrard JM, Pfeifer CG, Snee RD. Assessment of blood lead levels in the USA from NHANES II data. In: Consultants Ltd. International conference on heavy metals in the environment, Heidelberg, September 1983, Volume 1. Edinburgh 1983, pp 421-424.

16. Rabinowitz MB, Needleman HL. Temporal trends in the lead concentrations of umbilical cord blood. Science 216 (1982) 1429-1431.

17. Russel R, Stephens R. The contribution of lead in petrol to human lead intake. In: Rutter M, Jones RR, ed. Lead versus health - Sources and effects of low level lead exposure. John Wiley \& Sons, New York, NY 1983, pp $141-177$.
18. Rutter M, Jones RR, ed. Lead versus health - Sources and effects of low level lead exposure. John Wiley \& Sons, New York, NY 1983.

19. Schütz A. Cadmium and lead. Scand J Gastroenterol 14 (1979): suppl 52, 223-235.

20. Schütz A, Ranstam J, Skerfving S, Tejning S. Bloodlead levels in school children in relation to industrial emission and automobile exhausts. Ambio 13 (1984) $115-117$.

21. Slorach S, Gustafsson I-B, Jorhem L, Mattsson P. Intake of lead, cadmium and certain other metals via a typical Swedish weekly diet. Vår Föda 35 (1983): suppl 1.

22. Slorach S, Jorhem L. Tin and lead in foodstuffs. Vår Föda 34 (1982) 433-453.

23. Snee RD. Models for the relationship between blood lead and air lead. Int Arch Occup Environ Health 50 (1982) $303-319$.

24. Sörensen S, Cederlöf R, Engström B. Besvärsupplevelser vid bilavgasexponering [Annoyance reactions at the exposure of car exhaust]. National Institute of Environmental Medicine, Stockholm 1983. (SML report 1983: 5).

25. Stockholm's Municipal Environment and Health Administration. Undersökningar av fordonstrafikens luftföroreningar under 1982 [Investigations of air pollution from the traffic during 1982]. Stockholm 1983.

26. Vahter M, ed. Assessment of human exposure to lead and cadmium through biological monitoring. Report prepared for the United Nations Environment Programme and the World Health Organization by the National Swedish Institute of Environmental Medicine and Department of Environmental Health, Karolinska Institute, Stockholm 1982.

27. World Health Organization. Epidemiological study protocol on biological indicators of lead neurotoxicity in children. WHO Regional Office for Europe, Copenhagen 1983, pp 18-21. (ICP/RCE 903).

Received for publication: 11 September 1985 